\title{
INDUSTRIAL RESEARCH ASSOCIATIONS IN BRITAIN
}

"R ESEARCH for Industry, 1958", which reports on work done by the industrial research associations in the Government scheme, this year adopts a new pattern which has much to commend it. It includes the report of the Industrial Grants Committee of the Council for Scientific and Industrial Research which comprises a review of grant policy during 1957-64 (see p. 211 of this issue), and a review of the achievements during the past five years of the ten research associations to which new or revised terms of grant were recommended during the year. Apart from brief notes on any outstanding features of the work of other research associations during the period, the bulk of the report comprises a list of existing associations, giving their officers, total income and publications during the year and a brief note on the scope of the present work of each association. There is also an assessment by Dr. D. T. A. Townend of the place of the research associations in the evolution of scientific endeavour, and a report entitled "New Ideas, New Products, Now Processes" on how cooperation research serves the textile industries. In this report, which covers the work of several researeh associations, the point is made that one-fifth of an association's resources is only adequate for fundamental research if the total resources are big enough.

Of the research associations which received new or revised terms of grant during the year, stress is laid on the basic research into the composition of gelatin and glue, the structure of the gelatin molecule, the properties of solutions and gels and the conversion of collagen into gelatin being carried out by the British Gelatine and Glue Research Association; the economic value of the work of the British Hat and Allied Felt Makers' Research Association; the achievements of the British Hydromechanics Research Association in the design and utilization of pumps and in high-pressure hydraulic machinery and in hydraulic model testing. The Furniture Development
Council has conducted a basic investigation into factors affecting the strength and rigidity of cabinet construction, developed test methods for furniture lacquers and worked on a new, economical materialwood chipboard. The Heating and Ventilating Research Council began its first major research project in 1956-57-an investigation of problems arising from the intermittent heating of buildings, with the view of ascertaining possible fuel savings by choosing in advance equipment and programme of the daily heating cycle in relation to the thermal characteristics of the building and installation. The Lace Research Association has carried out much work on new types of yarn and on problems arising in dyeing and dressing synthetic fibre materials, and is engaged in a basic study of the bobbin and carriage, which is the central feature of major types of lace machines.

Basic research carried out by the British FlourMillers' Research Association includes a complete analysis of the amino-acid composition of flour and of the changes which occur when it is made into bread. The Research Association of British Rubber Manufacturers has extended its cover to plastics, notably polyvinyl chloride and polyethylene, and has been investigating the basic physical characteristics of rubber and plastics and the influence of service conditions such as temperature on these characteristics. An outstanding piece of chemical research increased knowledge of how traces of certain metals, notably copper and manganese, can cause premature deterioration of important classes of rubber products, especially rubber-proofed fabrics. The British Coke Research Association has developed instruments such as an isothermal bomb calorimeter for accurate determination of the calorific value of solid and liquid fuels and an electromagnetic semimicrobalance for use in fundamental studies relating to carbon.

\section{AGRICULTURAL RESEARCH IN BRITAIN}

\begin{abstract}
A CORRESPONDENT, commenting in a Scottish farming paper on the Report of the Agricultural Research Council for 1957-58, complained that he could find no reference to research on grass tetany. Because of its current seriousness, he felt that some of the four million pounds that the Council administers should be allocated directly towards research into this problem. If he had read the report with deeper understanding he would have realized that such a criticism was not really justified. For example, at the Rowett Research Institute there are in progress fundamental studies on the physiology of rumen digestion with particular reference to young grass which is high in potash and nitrogen. The work is not labelled grass tetany or hypomagneszmia, but it is in fact just the sort of work that will lead to a better understanding of the metabolic diseases of livestock which are still very largely unsolved. Agricultural research has long since passed from its old phase of an empirical approach to outatanding problems, and this is well illustrated by this report,
\end{abstract}

for the main emphasis is on fundamental studies necessary for a better understanding of the vital mechanisms of plants and animals.

Another illustration of this approach is provided by the investigations, mainly at Rothamsted Experimental Station and at the University of Durham, into the biology of the potato root eelworm. Studies have been made of diffusate from potato roots which stimulates hatching of the cysts, and investigations are proceeding at several centres into the chemistry of this material, with the view of obtaining a means of causing hatching in the absence of the host plant.

A feature of the report is the very considerable emphasis which is given to the several aspects of poultry research, which for a number of years was something of a Cinderella so far as the Council was concerned. The industry, with an annual output of $£ 200$ millions, is second in importance in Britain to dairying, and it also is one of the most heavily sub. sidized. It is very important that the industry 